\title{
Efficacy of caudal epidural injection of lidocaine, xylazine and xylazine plus hyaluronidase in reducing discomfort produced by electroejaculation in bulls
}

\author{
Ronaldo C. PAGLIOSA ${ }^{1)}$, Rafael DEROSSI ${ }^{2)}$, Deiler S. $\operatorname{COSTA}^{1)}$ and Fabio J.C. FARIA ${ }^{1)}$ \\ 1) Department of Animal Reproduction, Faculty of Veterinary Medicine and Animal Science, Federal University of Mato Grosso do Sul, \\ Brazil \\ 2) Department of Veterinary Medicine, Surgery and Anesthesiology, Faculty of Veterinary Medicine and Animal Science, Federal \\ University of Mato Grosso do Sul, Caixa Postal 549, Campo Grande, CEP 79070-900, MS, Brazil
}

(Received 15 July 2014/Accepted 18 May 2015/Published online in J-STAGE 22 June 2015)

ABSTRACT. To test the hypothesis that epidural administration of lidocaine, xylazine or xylazine plus hyaluronidase provides reduced pain and stress during electroejaculation in bulls, eight 30-month-old Nellore bulls received saline solution (control), $2 \%$ lidocaine, $2 \%$ xylazine or $2 \%$ xylazine plus hyaluronidase injected into the first intercoccygeal (Co1-Co2) epidural space in randomized order. Heart rate, respiratory rate, mean arterial pressure, analgesia, animal behavior and motor blockade were evaluated before treatment and at predetermined intervals during and after treatment. Pain and stress were scored subjectively, and semen quality was evaluated. The onset of anesthetic action was significantly faster with lidocaine $(3.0 \pm 1.2 \mathrm{~min})$ than with xylazine or xylazine plus hyaluronidase $(8.9 \pm 1.5$ and $5.5 \pm 2.6 \mathrm{~min}, P=0.021$ and $P=0.012$, respectively), and the onset of anesthesia with xylazine plus hyaluronidase was significantly faster than that with xylazine alone $(P=0.032)$. Treatment with xylazine or xylazine plus hyaluronidase resulted in less discomfort than treatment with lidocaine, as indicated by animal behavior. Changes in heart rate, respiratory rate and arterial pressure were within acceptable limits. Penile protrusion and semen emission occurred in all animals during all four treatments. Our results suggest that xylazine plus hyaluronidase reduced discomfort during electroejaculation more effectively than xylazine or lidocaine alone. Further experiments are necessary to determine whether electroejaculation with xylazine plus hyaluronidase is feasible for obtaining semen from Nellore bulls unaccustomed to being handled or restrained.

KEY WORDS: bull, electroejaculation, epidural analgesia, hyaluronidase, xylazine

doi: 10.1292/jvms.14-0369; J. Vet. Med. Sci. 77(11): 1339-1345, 2015

Among the various techniques used for collection of semen from animals, electroejaculation (EEJ) remains the most common method used for bulls (for breeding soundness evaluation, for example) and is particularly useful in animals that are not accustomed to the procedures in a breeding soundness exam. However, although EEJ is very effective in inducing semen emission, it is now considered to be painful and stressful to bulls and has been banned in several European countries [17, 19] owing to concerns about animal welfare (defined in terms of the "five freedoms," as cited by Mench [16]). Studies have been conducted for the purpose of measuring and decreasing pain associated with this necessary procedure $[14,15,17,19]$.

In men with normal sensation in the pelvic area, general or epidural anesthesia is used before EEJ [18], and the use of caudal epidural anesthesia in animals to reduce pain and stress due to EEJ has been studied. Serum cortisol and progesterone concentrations and heart rate (HR) tend to

\footnotetext{
*Correspondence to: Derossi R., Laboratory of Surgery and Anesthesiology, Department of Veterinary Medicine, Faculty of Veterinary Medicine and Animal Science, Federal University of Mato Grosso do Sul, Campo Grande, 79070-900, MS, Brazil. e-mail: rafael.rossi@ufms.br

(C)2015 The Japanese Society of Veterinary Science

This is an open-access article distributed under the terms of the Creative Commons Attribution Non-Commercial No Derivatives (by-nc-nd) License $<$ http://creativecommons.org/licenses/by-nc-nd/3.0/>.
}

be lower in bulls that receive caudal epidural anesthesia; however, anesthesia does not significantly reduce the stress response to EEJ [15]. Lidocaine is a local anesthetic that is routinely used for caudal epidural anesthesia in cattle during various reproductive procedures [14, 15, 17]. Other drugs, such as xylazine [17] and ketamine [12], are also used for this purpose. Caudal epidural xylazine might reduce the pain caused by rectal smooth muscle spasms or intrapelvic nerve stimulation [17], but this drug has the disadvantage of exhibiting delayed onset of analgesia [6, 7]. Hyaluronidase is hypothesized to hasten the onset of the block by enhancing the spread of local anesthesia $[10,25]$.

The purpose of this study was to evaluate the effectiveness of caudal epidural lidocaine, xylazine and xylazine plus hyaluronidase for reducing discomfort due to EEJ; caudal epidural saline solution was used as a control. HR, respiratory rate (RR) and mean arterial pressure (MAP) were used for evaluating systemic effects, and stress was evaluated by means of a subjective scale of behavioral responses. The degree of motor blockade was determined, and the effects of the anesthetics on penile protrusion, semen emission and semen quality were evaluated.

\section{MATERIALS AND METHODS}

Experimental animals: The experimental protocol of the present study was approved by the Ethics Committee for Animal Use of the Federal University of Mato Grosso do 
Sul (approval no. 473/2012). The experiments were conducted on eight 30-month-old Nellore bulls (Bos taurus indicus; 405-448 kg, mean $425 \mathrm{~kg}$ ) from which semen had not previously been collected. The bulls, which had been raised extensively, were habituated to a chute system by being brought into the chute for about $30 \mathrm{~min}$ a day for 1 week and offered food so that they remained calm and became familiar with the evaluators. The animals could move forward or backward or lie down within the chute. During the experimental period, the animals were pastured on Brachiaria spp., with water ad libitum, at the experimental farm of the Faculty of Veterinary Medicine and Animal Science, University of Mato Grosso do Sul. The ambient temperature was approximately $25^{\circ} \mathrm{C}$ during the experiments. Twentyfour hr before each EEJ experiment, the bulls were moved into stanchion stalls and clinically examined to confirm that they were healthy.

The first intercoccygeal epidural anesthesia: Each bull received the following four treatments, in random order, at minimum intervals of 7 days between treatments: saline solution $(0.9 \% \mathrm{NaCl}$, Ecoflax Plus, B. Braun, São Gonzalo, Brazil; control), 2\% lidocaine (Hypocaína 2\%, Hypofarma, Instituto de Hypodermia e Farmácia Ltda, Ribeião das Neves, Brazil) without epinephrine at a dose of $0.2 \mathrm{mg} / \mathrm{kg}, 2 \%$ xylazine (Xilazin 2\%, Syntec, Santana de Parnaiba, Brazil) at a dose of $0.05 \mathrm{mg} / \mathrm{kg}$ and $2 \%$ xylazine at a dose of $0.05 \mathrm{mg} / \mathrm{kg}$ plus 400 IU of hyaluronidase (Hyalozima, Apsen Farmacêutica S/A, São Paulo, Brazil). All the drugs were diluted in $0.9 \%$ saline to a final volume of $7 \mathrm{ml}$. Prior to drug administration, the skin area over the first intercoccygeal space was identified and aseptically prepared with $1 \%$ povidone iodine (PVPI, Vic Pharma Ind. Com. Ltda, Taquaritinga, Brazil) and infiltrated with $2 \mathrm{ml}$ of $2 \%$ lidocaine at the entry point. The drugs were administered at a rate of $0.5 \mathrm{ml} / \mathrm{sec}$ through a 12 $\mathrm{cm}, 16$-gauge Tuohy epidural needle (Perican, B. Braun, São Gonçalo, Brazil) placed between the first and second coccygeal vertebrae. Correct needle placement was confirmed by the hanging drop method or by loss-of-resistance method [24]. After drug administration, needles were flushed with $0.5 \mathrm{ml}$ of saline. Ten min after drug administration, EEJ and semen collection were performed as described below.

Procedure for EEJ: After transrectal examination of the accessory glands for $30 \mathrm{sec}$, bulls were appropriately restrained for EEJ. Conventional EEJ consisting of careful insertion of a conventional rectal probe with a diameter of $75 \mathrm{~mm}$ with 3 ventrally placed electrodes that emitted electrical stimuli from an electroejaculator (Duboi, Campo Grande, Brazil) was performed after rectal evacuation. After probe placement, a standardized sequence of electric pulses $(60 \mathrm{~Hz})$ was administered: 30 shortwaves between 100 and $300 \mathrm{~mA}$ (lasting 2-3 sec with $0.5 \mathrm{sec}$ intervals) followed by 2 long waves of up to $500 \mathrm{~mA}$ (lasting 3-5 sec). Emitted semen $(3 \mathrm{~m} l)$ was collected in Falcon tubes, and the time to drip (seminal plasma), time to semen emission (portion with spermatozoa) and the time to the end of EEJ (up to $3 \mathrm{ml}$ of ejaculate) were recorded. The mass motility, motility, vigor and sperm morphology of the collected semen samples were evaluated. Penile protrusion was evaluated during se- men emission according to the following scale: 0 , no penile protrusion; 1, 25\% protrusion; $2,50 \%$ protrusion; $3,75 \%$ protrusion; and 4, 100\% protrusion.

Evaluation of pain, discomfort and ataxia in bulls: The degrees of pain, discomfort and ataxia were evaluated by using scoring systems (Table 1) before the drug administration (baseline) and at 2, 10, 15, 20 and 30 min after drug administration. Since these scales are subjective, we took care to ensure that the assessments were performed by two trained, blinded observers. The time of onset, duration and intensity of pain relief were recorded. In a pilot study conducted previously, we established a needle prick test consisting of superficial and deep needle pricks on the tail and on the perineum and upper hind limbs and identified that the needle prick test was useful for the confirming analgesic effect produced by the first intercoccygeal epidural anesthesia. Pain relief produced by the epidural injections was confirmed by needle-prick tests. The bulls were evaluated for motor blockade or the presence of ataxia by being walked out of the stanchions after the epidural injections and after EEJ.

HR (beats/min), MAP and RR (breaths/min) were measured at 5 time points: $\mathrm{T}_{0}$, baseline; $\mathrm{T}_{\text {epi }}$, roughly equivalent to $2 \mathrm{~min}$ after drug administration; $\mathrm{T}_{\mathrm{EEJ}}$, roughly equivalent to $10 \mathrm{~min}$ after drug administration; $20 \mathrm{~min}$ after EEJ, roughly equivalent to $30 \mathrm{~min}$ after drug administration; and 30 min after the EEJ, roughly equivalent to 40 min after drug administration. Arterial blood pressure was measured with a cardiac monitor (EMAI RX-300, Transmai, Hospital Medical Equipment, São Paulo, Brazil) by using a noninvasive measurement device with a cuff (12 to $19 \mathrm{~cm}$ wide) attached to the proximal third of the tail to measure the pressure of the coccygeal artery [11-13]. Salivation and urination frequency were also observed.

Statistical analysis: All data were analyzed by use of a statistical analysis program (SAS 6.12, SAS Institute Inc., Cary, NC, U.S.A.). A randomized complete block design was used for each drug, with time as a treatment and each of the 8 bulls as a block. For dependent variables (HR, MAP and RR), a 2-way parametric ANOVA was performed, and a post hoc Dunnett test was performed when the treatment response differed from baseline values. For pain, discomfort and ataxia, scores were analyzed by use of nonparametric procedures (Friedman test) followed by multiple comparisons for data in rank by use of the Dunnett test. In each analysis, differences were considered significant at values of $P<0.05$.

\section{RESULTS}

We took care that all the bulls received similar electrical stimulations during all EEJ procedures. In all the bulls, the Tuohy needle was placed without difficulty, and EEJ was performed without complication. We considered that pain relief was achieved when the bulls did not respond to needle pricks (i.e., a score of 2 or 3 in the pain score). No bull showed pain relief or reduction in discomfort produced by the needle prick test after the control treatment, while all the animals achieved satisfactory pain relief after epidural injection with lidocaine, xylazine or xylazine plus hyaluronidase. 
Table 1. Scoring system for evaluating pain, discomfort and ataxia in bulls

\begin{tabular}{|c|c|}
\hline Scores & Definition of scoring \\
\hline \multicolumn{2}{|c|}{ Pain score } \\
\hline 3 & Complete analgesia, animals calm and indifferent to a noxious stimulus or during EEJ. \\
\hline 2 & Analgesia, without reaction to a noxious stimulus or during EEJ but with some discomfort. \\
\hline 1 & $\begin{array}{l}\text { Mild analgesia, smaller reaction to a noxious stimulus or during EEJ but restlessness and movement with no kicking } \\
\text { demonstrating irritation. }\end{array}$ \\
\hline 0 & Painful response, with a strong reaction to a noxious stimulus* or during EEJ $\dagger$, movements of struggle and reluctance. \\
\hline \multicolumn{2}{|r|}{ Discomfort score } \\
\hline 3 & No discomfort, no attempt to escape, no attempt to lie down, no vocalization. \\
\hline 2 & $\begin{array}{l}\text { Mild discomfort, one escape attempt, discomfort but with normal standing position (staying up on } 4 \text { feet) and vocaliza- } \\
\text { tion not too high. }\end{array}$ \\
\hline 1 & $\begin{array}{l}\text { Moderate discomfort, two or three escape attempts, presence of head butts and kicks, flexion of the carpal joint or two } \\
\text { or three vocalization obvious and not very loud. }\end{array}$ \\
\hline 0 & $\begin{array}{l}\text { Severe discomfort, four or more escape attempts, moderate strong kicking on first } 5 \text { electrical impulses, going down on } \\
\text { carpal joint and four or more loud bellows. }\end{array}$ \\
\hline \multicolumn{2}{|r|}{ Ataxia score } \\
\hline 3 & No ataxia. \\
\hline 2 & Mild ataxia, slight stumbling, no tail movements, loss of anal reflex, easily able to continue walking. \\
\hline 1 & Moderate ataxia, marked stumbling while walking but very ataxic. \\
\hline 0 & Severe ataxia, falling. \\
\hline
\end{tabular}

The onset of pain relief demonstrated by the needle-prick test was significantly faster with lidocaine $(3.0 \pm 1.2 \mathrm{~min}$, mean \pm standard deviation) than with xylazine or xylazine plus hyaluronidase $(8.9 \pm 1.5$ and $5.5 \pm 2.6 \mathrm{~min}, P=0.021$ and $P=0.012$, respectively). The time to onset of pain relief with xylazine plus hyaluronidase was significantly shorter than that with xylazine alone $(P=0.032)$ (Fig. $1 \mathrm{~A})$.

During EEJ (10 to 15 min after the epidural injection), the bulls receiving the control treatment demonstrated a severe degree of pain (median score 0) and discomfort (median score 0 ). In contrast, the bulls receiving the epidural injection with lidocaine, xylazine or xylazine plus hyaluronidase demonstrated mild pain (median score of 2) and discomfort (median score of 2) during EEJ. Despite a certain degree of discomfort that was not statistically significant, the animals in the xylazine, lidocaine and xylazine plus hyaluronidase groups behaved more calmly during EEJ than the bulls in the control group (Fig. 1B).

Complete loss of tail muscle tone and loss of anal reflex occurred in the lidocaine, xylazine and xylazine plus hyaluronidase groups, but none of the bulls showed caudal ataxia due to the epidural injections. None of the bulls attempted to lie down during any of the treatments. However, two bulls in the xylazine group and one bull in the xylazine plus hyaluronidase group lay down temporarily after leaving the chute restraint. Five bulls in the xylazine group and 4 bulls in the xylazine plus hyaluronidase group salivated moderately; none of the bulls in any of the groups showed an increase in urination during the observation period.

The effects of the treatments on HR, RR and MAP are shown in Table 2. The control and lidocaine caudal epidural injections induced no significant change in HR at any point during the observation period. The xylazine and xylazine plus hyaluronidase treatments induced no significant change in HR when compared with the baseline values; however, at 20 and 30 min after EEJ (i.e., 30 and 40 min after epidural injection), the HRs in the xylazine and xylazine plus hyaluronidase groups were significantly lower than those in the control group at the same measurement times. None of the treatments induced significant changes in MAP during the observation period. In the control and lidocaine groups, there were no significant changes in RR compared with baseline. In contrast, in the xylazine and xylazine plus hyaluronidase groups, the RRs at 20 and $30 \mathrm{~min}$ after EEJ were significantly lower than the corresponding baseline RRs $(P=0.017$ and $P=0.002$, respectively).

Semen was collected from all bulls during conventional probe EEJ with all 4 epidural treatments, and penile protrusion and semen emission occurred in all animals. The most common extent of penile protrusion was $25 \%$ for all treatments. Time to drip, time to semen emission, time to end of EEJ and semen characteristics (motility, vigor, mass motility and morphology) are shown in Table 3. There was no significant difference in time to semen emission or in semen characteristics of the bulls between the control and lidocaine, xylazine and xylazine plus hyaluronidase treatments.

\section{DISCUSSION}

In this study, we evaluated the onset of analgesia and the analgesic efficacy of lidocaine, xylazine and xylazine plus hyaluronidase epidurally administered to bulls to determine whether these drugs decreased stress or pain associated with EEJ. When epidurally administered, lidocaine and xylazine have different mechanisms of action for analgesia. Lidocaine is a local anesthetic that acts on the cell membrane sodium channels by inhibiting transmission of noxious stimuli, and xylazine is an alpha-2 adrenoceptor agonist that produces an 

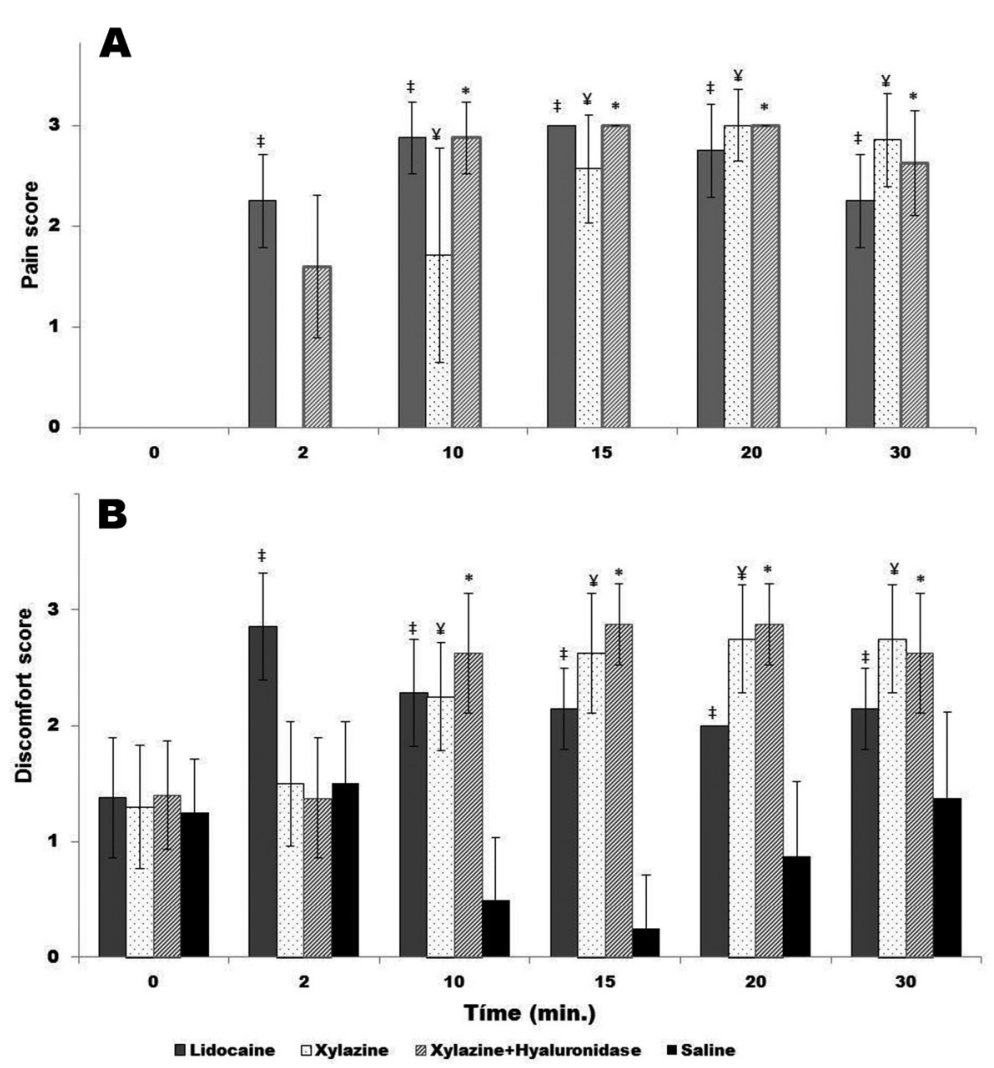

Fig. 1. Median ( \pm quartile deviation) pain (A) and discomfort (B) scores in 8 bulls that underwent needle noxious stimulus and electroejaculation (EEJ) with epidural administration of saline $(0.9 \% \mathrm{NaCl}$; control), $2 \%$ lidocaine $(0.2 \mathrm{mg} / \mathrm{kg}), 2 \%$ xylazine $(0.05 \mathrm{mg} / \mathrm{kg})$ or $2 \%$ xylazine plus hyaluronidase $(0.05 \mathrm{mg} / \mathrm{kg}+400 \mathrm{IU}$, respectively). Pain was scored by use of the following scale: 0, painful response, with a strong reaction to a noxious stimulus or during EEJ, movements of struggle and reluctance; 1, mild analgesia, smaller reaction to a noxious stimulus or during EEJ but restlessness and movement with no kicking demonstrating irritation; 2, analgesia, without reaction to a noxious stimulus or during EEJ but with some discomfort; and 3, complete analgesia, animals calm and indifferent to a noxious stimulus or during EEJ. Discomfort was scored by use of the following scale: 0 , severe discomfort, 4 or more escape attempts, moderate strong kicking on first 5 electrical impulses, going down on carpal joint and 4 or more loud bellows; 1, moderate discomfort, 2 or 3 escape attempts, presence of head butts and kicks, flexion of the carpal joint or 2 or 3 vocalization obvious and not very loud; 2, mild discomfort, one escape attempt, discomfort but with normal standing position (staying up on 4 feet) and vocalization not too high; and 3, normal reaction, no attempt to escape, no attempt to lie down, no vocalization. The values for lidocaine $(\ddagger)$, xylazine $(¥)$ and xylazine plus hyaluronidase $(*)$ differed significantly $(P<0.05)$ from the respective baseline (time 0 ) values. The values for the saline group (control) did not differ significantly $(P<0.05)$ from the respective baseline (time 0$)$ values.

analgesic effect via stimulation of the alpha-2 adrenoceptor in the spinal cord. We started from the assumption that xylazine administered by epidural would have analgesic and sedative effects after systemic absorption from the epidural space. Epidural administration of xylazine is known to produce delayed-onset analgesia [6, 7]. In dogs, the time to onset of anesthesia with epidural hyaluronidase combined with levobupivacaine is significantly shorter than that with epidural levobupivacaine alone [10]. In our study, a clear improvement in animal well-being during EEJ was observed in the bulls administered epidural lidocaine, xylazine or xylazine combined with hyaluronidase. In addition, epidural xylazine combined with hyaluronidase produced a rapid onset of analgesia compared with epidural xylazine alone.

Several alternative methods to reduce pain and stress during EEJ are currently being explored for humanitarian reasons $[17,19]$. Stress is directly related to physiological (neural and endocrine) and behavioral responses that tend to reestablish homeostasis [23], and pain is manifested by a rapid reaction with aversion to actual or imminent tissue damage, resulting in physiologic, neuroendocrine and behavioral changes that indicate a stress response [8]. Conscious animals demonstrate pain or stress in response to EEJ, especially when higher levels of electrical stimulation are used [17]. EEJ without anesthesia has been discouraged or banned in several European countries, and the importation of semen collected by EEJ was prohibited by the European Union for several years in the 1990s [17, 21]. The oldest method for obtaining semen from bulls is the use of an artificial vagina or an internal artificial vagina (a device designed 
Table 2. Cardiovascular values and respiratory rate in eight bulls receiving epidural saline, lidocaine, xylazine and xylazine plus hyaluronidase and undergoing electroejaculation with a rectal conventional probe $($ mean $\pm \mathrm{SD})$

\begin{tabular}{|c|c|c|c|c|c|}
\hline \multirow{2}{*}{ Treatments } & \multicolumn{5}{|c|}{ Time (min) } \\
\hline & $\mathrm{T}_{0}$ & $\mathrm{~T}_{\text {epi }}$ & $\mathrm{T}_{\mathrm{EEJ}}$ & 30 & 40 \\
\hline \multicolumn{6}{|l|}{ HR } \\
\hline Saline & $79 \pm 12$ & $82 \pm 9$ & $88 \pm 14$ & $91 \pm 13$ & $87 \pm 1$ \\
\hline Lidocaine & $79 \pm 9$ & $80 \pm 10$ & $87 \pm 11$ & $82 \pm 12$ & $77 \pm 13$ \\
\hline Xylazine & $76 \pm 16$ & $74 \pm 12$ & $76 \pm 15$ & $67 \pm 9^{*}$ & $65 \pm 12 *$ \\
\hline Xylazine plus hyaluronidase & $79 \pm 14$ & $80 \pm 12$ & $82 \pm 14$ & $69 \pm 10^{*}$ & $69 \pm 14^{*}$ \\
\hline \multicolumn{6}{|l|}{ MAP } \\
\hline Saline & $132 \pm 23$ & $122 \pm 15$ & $114 \pm 14$ & $115 \pm 20$ & $112 \pm 14$ \\
\hline Lidocaine & $119 \pm 25$ & $124 \pm 21$ & $122 \pm 18$ & $119 \pm 13$ & $112 \pm 17$ \\
\hline Xylazine & $127 \pm 22$ & $120 \pm 17$ & $118 \pm 21$ & $120 \pm 19$ & $114 \pm 29$ \\
\hline Xylazine plus hyaluronidase & $113 \pm 15$ & $115 \pm 14$ & $116 \pm 16$ & $100 \pm 10$ & $100 \pm 11$ \\
\hline \multicolumn{6}{|l|}{$\mathrm{RR}$} \\
\hline Saline & $34 \pm 7$ & $32 \pm 6$ & $30 \pm 5$ & $29 \pm 5$ & $37 \pm 3$ \\
\hline Lidocaine & $34 \pm 5$ & $31 \pm 8$ & $33 \pm 7$ & $31 \pm 9$ & $36 \pm 8$ \\
\hline Xylazine & $34 \pm 9$ & $29 \pm 10$ & $27 \pm 8$ & $23 \pm 6^{\mathrm{a})}$ & $20 \pm 7^{\mathrm{a})}$ \\
\hline Xylazine plus hyaluronidase & $35 \pm 6$ & $36 \pm 11$ & $33 \pm 14$ & $28 \pm 12^{\mathrm{a})}$ & $22 \pm 13^{a)}$ \\
\hline
\end{tabular}

$\mathrm{T}_{0}$, basal time; $\mathrm{T}_{\text {epi }}$, time after epidural injections; $\mathrm{T}_{\mathrm{EEJ}}$, time after conventional electroejaculation; $\mathrm{HR}$, heart rate in beats/min; MAP, mean arterial blood pressure in $\mathrm{mm} \mathrm{Hg} ; \mathrm{RR}$, respiratory rate in breaths/ $\mathrm{min}$; saline, $0.9 \%$ saline solution; lidocaine, $0.2 \mathrm{mg} / \mathrm{kg}$; xylazine, $0.05 \mathrm{mg} / \mathrm{kg}$ xylazine; xylazine plus hyaluronidase, $0.05 \mathrm{mg} / \mathrm{kg}$ xylazine plus 400 UI hyaluronidase. * Significantly different $(P<0.05)$ from control group (SS) by time, ${ }^{\text {a }}$ Significantly different $(P<0.05)$ from baseline.

Table 3. Mean $( \pm \mathrm{SD})$ time to drip and semen emission and seminal characteristics for electroejaculation after epidural treatments in bulls $(\mathrm{n}=8)$

\begin{tabular}{lcccc}
\hline & \multicolumn{3}{c}{ Treatments } \\
\cline { 2 - 5 } & Saline & Lidocaine & Xylazine & Xylazine plus hyaluronidase \\
\hline Time to drip $(\mathrm{sec})$ & $28.9 \pm 12.0$ & $27.9 \pm 8.3$ & $13.7 \pm 6.4$ & $21.0 \pm 11.8$ \\
Time to semen emission $(\mathrm{sec})$ & $57.4 \pm 13.0$ & $52.1 \pm 17.9$ & $32.1 \pm 6.0$ & $38.0 \pm 18.3$ \\
End of EEJ $(\mathrm{sec})$ & $83.0 \pm 21.7$ & $69.6 \pm 36.5$ & $50.5 \pm 28.9$ & $58.9 \pm 43.0$ \\
Percent motile sperm & $61.8 \pm 18.8$ & $60.6 \pm 22.0$ & $62.8 \pm 14.1$ & $78.5 \pm 14.0$ \\
Vigor sperm & $3.2 \pm 1.3$ & $3.2 \pm 1.7$ & $3.5 \pm 1.0$ & $4.4 \pm 1.0$ \\
Mass motility & $1.6 \pm 1.7$ & $2.0 \pm 1.9$ & $2.2 \pm 1.3$ & $3.0 \pm 1.4$ \\
Morphology of sperm $\dagger$ & $15.5 \pm 14.1$ & $17.1 \pm 19.0$ & $19.7 \pm 19.4$ & $17.1 \pm 18.0$ \\
\hline
\end{tabular}

* Until obtaining $3 \mathrm{~m} l$ of semen. $\uparrow$ Total sperm abnormalities. $(P>0.05)$

to fit within the vagina of a live cow) [2]. Advantages of the latter include the elimination of incubators, curtains and intense human involvement in the semen collection process [2]. However, the internal artificial vagina is not as effective as EEJ for collecting semen from range bulls, and the procedure can lead to the spread of venereal disease and can endanger the welfare of mount cows that are restrained for long periods of time and served by multiple bulls. Many veterinarians use transrectal massage for collecting semen from bulls, but there are few descriptions of this method in the literature; this method is a viable alternative to EEJ in docile bulls [2]. In a study of mature and yearling bulls, the index of penile protrusion was much lower during transrectal massage (54.4\% and $15.4 \%$, respectively) than during EEJ ( $91.5 \%$ and $89.7 \%$, respectively). Insufficient penile protrusion decreases semen quality, because the semen is exposed to the hostile environment of the prepuce [2]. Drugs, such as oxytocin, prostaglandin $\mathrm{F}_{2 \alpha}$ and cloprostenol, are sometimes used as adjuvants during transrectal massage [20, 21] and EEJ [3] to improve the quality of samples obtained for breeding soundness evaluation. All of the above-described methods offer advantages and disadvantages for the collection of semen from mature or yearling bulls.

We worked with young bulls from which semen had not previously been collected, and we observed that aversive behavior was moderately diminished during EEJ in bulls that received xylazine or xylazine plus hyaluronidase treatments. The lidocaine, xylazine and xylazine plus hyaluronidase treatments abolished pain observed by painful needle prick test when compared with EEJ with the saline treatment. Our results were probably due not to the presence of pain after the EEJ procedure but to the sedative effect of xylazine after absorption from the epidural space. In one study, HR elevation due to treatment with intrarectal lidocaine was similar to 
that observed during conventional EEJ; this result indicates that pain during EEJ is likely due not to spasm of the rectal smooth muscle but to strong nerve stimulation [17].

Bulls of European origin (Bos taurus taurus) are less responsive to handling than bulls of Asian origin (Bos taurus indicus), as indicated by differences in behavioral changes (vocalization, struggling or attempts to lie down) or reaction to painful stimuli (venipuncture and intramuscular injection), and this difference makes it difficult to interpret the degree of pain or stress experienced during EEJ in European bulls. Several studies have indicated that EEJ induces physiological, neuroendocrine and behavioral changes that may indicate a stress response associated with pain $[14,15,21]$. Blood levels of cortisol and progesterone are considered to be objective indicators of pain in ruminants $[9,15,22,26]$. However, tests to measure these concentrations are expensive and not feasible under the field conditions frequently encountered by veterinarians. Moreover, simple veterinary procedures, such as rectal palpation and intramuscular injection, are sufficient to increase blood cortisol levels in cattle [1]. Whitlock et al. [27] observed greater vocalizations and higher mean cortisol and progesterone concentrations following EEJ in bulls; however, no increase in plasma substance $\mathrm{P}$ concentration, which is a more accurate indicator of pain associated with EEJ, was observed. On the basis of the lack of change in the concentration of substance P after EEJ, Whitlock et al. [27] suggested that EEJ may not be a painful procedure. The increases in hormone (cortisol and progesterone) concentrations described in previous studies may not be directly related to pain or stress, because an increase in plasma cortisol concentration similar to the increase observed during EEJ in bulls has also been observed during mounting and servicing activities [5, 26].

HR, RR and MAP are physiological parameters considered to be related to pain. In a study of mature bulls (Horned Hereford, Simmental and South Devon), no change in HR from baseline was observed after EEJ with various treatments, including epidural lidocaine and xylazine, and these results may indicate that the pain due to EEJ in bulls is not severe [17]. At the anesthetic doses in our study, no significant changes in HR or MAP were observed during any of the treatments, although HR tended to be higher in the control and lidocaine groups than in the xylazine and xylazine plus hyaluronidase groups. Epidural administration of xylazine in cattle produces hypoventilation with increased carbon dioxide and decreased oxygen partial pressures in arterial blood [7]. We did not analyze blood gases in our study, but both treatments containing xylazine resulted in a decrease in RR after epidural administration and EEJ. We believe that the animals' lying down after they left the chute was due not to ataxia of the hind limbs but to the systemic effect of sedation induced by absorption of xylazine from the epidural space. A human study involving clonidine, an alpha-2 agonist, administered by epidural and intramuscular routes demonstrated that the onset of analgesia and the adverse effects of the drug coincide with the peak plasma concentration [4]. In contrast to local anesthetics, alpha-2 adrenoceptor agonists produce analgesia with minimal proprioception deficits or motor nerve blockade [24]. Therefore, there may be a relationship between the decreases in HR and RR and the sedation caused by the absorption of xylazine. Another adverse effect of epidural xylazine observed in this study was the presence of moderate salivation in some animals. These facts suggest, but do not allow us to conclude, that epidural xylazine may be better for reducing pain or stress during EEJ than the control and lidocaine in bulls. In humans, lumbosacral epidural anesthesia is used to prevent pain during EEJ [18], but the caudal epidural anesthesia ( $\mathrm{Co} 1-\mathrm{Co} 2)$ used in large animals may not involve all the nerve fibers affected by the EEJ procedure.

Epidural administration of saline, lidocaine, xylazine or xylazine plus hyaluronidase had no adverse effects on penile protrusion and did not interfere with semen emission during EEJ. All the bulls showed penile protrusion with all treatments, with $25 \%$ being the most common extent of protrusion. The time and number of impulses required for emission of a semen sample were similar for all treatments, and none of the treatments affected spermatogenesis. In a previous study [17], similar results were obtained with epidural lidocaine and xylazine after EEJ with regard to penile protrusion and semen emission in bulls; however, in the same study, transrectal massage alone caused only partial penile protrusion in all bulls and did not cause semen emission in any of the bulls. Transrectal massage prior to EEJ is believed to stimulate semen emission, but this practice is not commonly used in bulls that are unaccustomed to being handled or restrained. In a study of extremely docile bulls after administration of oxytocin and intramuscular cloprostenol, EEJ seemed to be slightly more successful than transrectal massage, and penile protrusion rates were comparable between the 2 methods [20].

The design of this study has some limitations. We did not have a control treatment involving the insertion of a rectal probe without electrical stimulation. However, other studies in bulls have indicated that this control treatment has minimal side effects $[26,27]$. Another limiting factor was that we did not draw blood samples for determination of hormone (cortisol and progesterone) concentrations at predetermined intervals, so we could not determine whether epidural anesthesia with lidocaine, xylazine and xylazine plus hyaluronidase altered plasma levels of these hormones after EEJ in bulls. Cortisol and progesterone concentrations have been reported to be significantly elevated after EEJ, whether or not bulls receive caudal epidural anesthesia [14]. Various routine procedures in cattle, both invasive and noninvasive procedures, such as rectal palpation, intramuscular injections, venipuncture and mounting and servicing activities, have been observed to result in increased plasma cortisol concentrations similar to those observed during EEJ in bulls $[1,5,26]$.

On the basis of our current results, we cannot say with certainty that the studied methods eliminated pain or stress during EEJ in bulls. However, on the basis of analgesia; HR, RR and MAP remaining within acceptable limits; and behavior (little vocalization, no attempts to lie down and little struggling), we can suggest that the caudal epidural anesthesia 
with xylazine or xylazine plus hyaluronidase may be more effective than caudal epidural anesthesia with lidocaine. The anesthetics did not interfere with semen emission, penile protrusion or spermatogenesis. Further experiments will be necessary to determine whether EEJ with xylazine plus hyaluronidase is feasible for semen emission from Nellore bulls that are not accustomed to being handled or restrained.

\section{REFERENCES}

1. Alam, M. G. S. and Dobson, H. 1986. Effect of various veterinary procedures on plasma concentrations of cortisol, luteinizing hormone and prostaglandin F2-alpha metabolite in the cow. Vet. Rec. 118: 7-10. [Medline] [CrossRef]

2. Barth, A. D., Arteaga, A. A., Brito, L. F. C. and Palmer, C. W. 2004. Use of internal artificial vaginas for breeding soundness evaluation in range bulls: an alternative for electroejaculation allowing observation of sex drive and mating ability. Anim. Reprod. Sci. 84: 315-325. [Medline] [CrossRef]

3. Berndtson, W. E. and Igboeli, G. 1988. Spermatogenesis, sperm output and seminal quality of Holstein bulls electroejaculated after administration of oxytocin. J. Reprod. Fertil. 82: 467-475. [Medline] [CrossRef]

4. Bonnet, F., Boico, O., Rostaing, S., Loriferne, J. F. and Saada, M. 1990. Clonidine-induced analgesia in postoperative patients: epidural versus intramuscular administration. Anesthesiology 72: 423-427. [Medline] [CrossRef]

5. Borg, K. E., Esbenshade, K. L. and Johnson, B. H. 1991. Cortisol, growth hormone, and testosterone concentrations during mating behavior in the bull and boar. J. Anim. Sci. 69: 3230-3240. [Medline]

6. Caron, J. P. and LeBlanc, P. H. 1989. Caudal epidural analgesia in cattle using xylazine. Can. J. Vet. Res. 53: 486-489. [Medline]

7. Caulkett, N., Cribb, P. H. and Duke, T. 1993. Xylazine epidural analgesia for cesarean section in cattle. Can. Vet. J. 34: 674-676. [Medline]

8. Coetzee, J. F., Lubbers, B. V., Toerber, S. E., Gehring, R., Thomson, D. U., White, B. J. and Apley, M. D. 2008. Plasma concentrations of substance $\mathrm{P}$ and cortisol in beef calves after castration or simulated castration. Am. J. Vet. Res. 69: 751-762. [Medline] [CrossRef]

9. Cooper, C., Evans, A. C. O., Cook, S. and Rawlings, N. C. 1995. Cortisol, progesterone and beta-endorphin response to stress in calves. Can. J. Anim. Sci. 75: 197-201. [CrossRef]

10. DeRossi, R., de Barros, A. L. C., Silva-Neto, A. B., Pompermeyer, C. T. and Frazílio, F. O. 2011. Hyaluronidase shortens levobupivacaine lumbosacral epidural anaesthesia in dogs. $J$. Small Anim. Pract. 52: 195-199. [Medline] [CrossRef]

11. DeRossi, R., Bertoni, R. A., Ruzzon, R. H. S., Verde-Selva, A. B. and Frazílio, F. O. 2010. Segmental dorsolumbar epidural analgesia via the caudal approach using multiple port catheters with ketamine or lidocaine or in combination in cattle. Vet. Anaesth. Analg. 37: 451-459. [Medline] [CrossRef]

12. DeRossi, R., Zanenga, N. F., Alves, O. D., Carneiro, R. P. B., Ossuna, M. R. and Jorge, T. P. 2010. Effects of caudal epidural ketamine and/or lidocaine on heifers during reproductive pro- cedures: A preliminary study. Vet. $J$. 185: $344-346$. [Medline] [CrossRef]

13. DeRossi, R., Verde-Selva, A. B., Bertoni, R. A., Ruzzon, R. H. S. and Silva-Neto, A. B. 2010. Lignocaine versus bupivacaine for flank anaesthesia using multiport catheters via a caudal epidural approach in cattle. Aust. Vet. J. 88: 362-367. [Medline] [CrossRef]

14. Etson, C. J., Waldner, C. L. and Barth, A. D. 2004. Evaluation of a segmented rectal probe and caudal epidural anesthesia for electroejaculation of bulls. Can. Vet. J. 45: 235-240. [Medline]

15. Falk, A. J., Waldner, C. L., Cotter, B. S., Gudmundson, J. and Barth, A. D. 2001. Effects of epidural lidocaine anesthesia on bulls during electroejaculation. Can. Vet. J. 42: 116-120. [Medline]

16. Mench, J. A. 1998. Farm animal welfare, pp. 170-171. In: Encyclopedia of Animal Rights and Animal Welfare (Bekoff, M. ed.), Greenwood Press, Westport.

17. Mosure, W. L., Meyer, R. A., Gudmundson, J. and Barth, A. D. 1998. Evaluation of possible methods to reduce pain associated with electroejaculation in bulls. Can. Vet. J. 39: 504-506. [Medline]

18. Ohl, D. A. 1993. Electroejaculation. Urol. Clin. North Am. 20: 181-188. [Medline]

19. Palmer, C. W. 2005. Welfare aspects of theriogenology: investigating alternatives to electroejaculation of bulls. Theriogenology 64: 469-479. [Medline] [CrossRef]

20. Palmer, C. W., Amundson, S. D., Brito, L. F. C., Waldner, C. L. and Barth, A. D. 2004. Use of oxytocin and cloprostenol to facilitate semen collection by electroejaculation or transrectal massage in bulls. Anim. Reprod. Sci. 80: 213-223. [Medline] [CrossRef]

21. Palmer, C. W., Brito, L. F. C., Arteaga, A. A., Söderquist, L., Persson, Y. and Barth, A. D. 2005. Comparison of electroejaculation and transrectal massage for semen collection in range and yearling feedlot beef bulls. Anim. Reprod. Sci. 87: 25-31. [Medline] [CrossRef]

22. Robertson, I. S. 1994. Effect of different methods of castration on behavior and plasma cortisol in calves of three ages. Res. Vet. Sci. 56: 8-17. [Medline] [CrossRef]

23. Sapolsky, R. M. 2004. Social status and healthy in humans and others animals. Annu. Rev. Anthropol. 33: 393-418. [CrossRef]

24. Skarda, R. T. and Tranquilli, W. J. 2007. Local and regional anesthetic and analgesic techniques: ruminants and swine pp. 643-680. In: Lumb \& Jones' Veterinary Anesthesia and Analgesia, 4th ed. (Tranquilli W. J, Thurmon, J.C. and Grimm, K. A, eds.), Blackwell Publishing Ames.

25. Watson, D. 1993. Hyaluronidase. Br. J. Anaesth. 71: 422-425. [Medline] [CrossRef]

26. Welsh, T. H. Jr. and Johnson, B. H. 1981. Stress-induced alterations in secretion of corticosteroids, progesterone, luteinizing hormone, and testosterone in bulls. Endocrinology 109: 185-190. [Medline] [CrossRef]

27. Whitlock, B. K., Coffman, E. A., Coetzee, J. F. and Daniel, J. A. 2012. Electroejaculation increased vocalization and plasma concentrations of cortisol and progesterone, but not substance $\mathrm{P}$, in beef bulls. Theriogenology 78: 737-746. [Medline] [CrossRef] 